\title{
ANGKA KEJADIAN PENDERITA FRAKTUR TULANG FASIAL DI SMF BEDAH BLU RSU PROF. R.D. KANDOU PERIODE JANUARI 2012 - DESEMBER 2012
}

\author{
${ }^{1}$ Christo Kairupan \\ ${ }^{2}$ A. Monoarfa \\ ${ }^{2}$ J. Ngantung \\ ${ }^{1}$ Mahasiswa Fakultas Kedokteran Universitas Sam Ratulangi Manado
${ }^{2}$ Dosen Bagian Bedah Fakultas Kedokteran Universitas Sam Ratulangi Manado
Email: christokairupan@yahoo.com
}

Abstract: Facial Trauma, also known as maxillofacial trauma, is a forced to the face. Trauma maxillofacial occurred about $6 \%$ of all trauma. Trauma Facial causing fractures facial that happen a lot. Facial fractures occur because of trauma load that is greater than facial bones resistance. Facial fractures are divided into several parts, the nasal bone fracture, fracture zygoma and zygoma arch, maxilla fractures, orbital fractures and fractures of the mandible. With the increase of people's mobilization and a growing level of transportation, causing accident that led to increased facial trauma. The research objective was to determine the incidence of facial fractures in patients SMF BLU Surgical Hospital Prof. R. D. Kandou the period January 2012 to December 2012. Research method: Retrospective descriptive study of the medical records in SMF BLU Surgical Hospital Prof. Dr. R.D. Kandou Manado from January 2012 to December 2012 is used in this paper. Result: Number of patients with facial fractures who were treated at the Surgical SMF period January 2012-December 2012 as many as 156 cases $(5.60 \%)$ of the total of 2786 treated facial trauma. Most facial fractures age are $20-29$ years that is $78(50.00 \%)$, men are more than women that 132 cases (84.62\%); most private sector employees work as many as 40 cases (25.64\%), the highest in the District Malalayang by 49 cases $(31.41 \%)$, the most common cause of traffic accidents as many as 82 cases (52.56\%), as well as the location of the mandibular bone fracture is the most, 72 cases (39.77\%). Conclusion: Trauma face causing facial fractures that went on SMF Surgical Hospital Prof R. D. Kandou still quite high, so it is necessary to continually educate people to avoid the possibility of injury in day-to-day activities.

Keywords: facial trauma, facial fractures, facial bones.

\begin{abstract}
Abstrak: Trauma fasial disebut juga trauma maksilofacial adalah trauma akibat ruda paksa terhadap wajah. Trauma maksilofacial terjadi sekitar 6\% dari seluruh trauma. Trauma fasial menyebabkan fraktur fasial yang banyak terjadi. Fraktur tulang fasial terjadi karena beban trauma yang lebih besar dari tahanan tulang fasial. Fraktur fasial dibagi menjadi beberapa bagian, yaitu fraktur tulang hidung, fraktur zigoma dan arkus zigoma, fraktur maksila, fraktur orbita dan fraktur mandibula. Dengan peningkatan mobilisasi penduduk serta tingkat transportasi yang berkembang, menyebabkan insiden kecelakaan yang menyebabkan trauma fasial meningkat. Tujuan penelitian adalah Untuk mengetahui angka kejadian penderita fraktur tulang fasial di SMF Bedah BLU RSU Prof. R. D. Kandou periode Januari 2012 sampai Desember 2012. Metode penelitian: metode retrospektif deskriptif melalui penelitian data rekam medik di SMF Bedah BLU RSU Prof. Dr. R.D. Kandou Manado periode Januari 2012 sampai Desember 2012. Hasil penelitian: Jumlah penderita fraktur fasial yang dirawat di SMF Bedah periode Januari 2012-Desember 2012 sebanyak 156 kasus (5,60\%) dari total 2786 trauma fasial yang dirawat. Usia terbanyak fraktur fasial 20-29 tahun yaitu 78 (50,00\%); pria lebih banyak wanita yaitu 132 kasus (84,62\%); dari pekerjaan paling banyak pegawai swasta sebanyak 40 kasus (25,64\%); terbanyak di Kecamatan Malalayang sebesar 49 kasus (31,41\%); penyebab terbanyak akibat kecelakaan lalulintas yaitu sebanyak 82 kasus (52,56\%); serta lokasi fraktur terbanyak adalah tulang mandibula sebanyak 72 kasus (39,77\%). Simpulan: Trauma wajah yang menyebabkan fraktur fasial yang masuk di SMF bedah RSU Prof R. D. Kandou masih cukup tinggi, sehingga diperlukan edukasi terus menerus kepada masyarakat agar menghindari kemungkinan terjadinya trauma, dalam kegiatan sehari-hari.
\end{abstract}

Kata kunci: trauma fasial, fraktur fasial, tulang-tulang wajah. 
Trauma fasial disebut juga trauma maksilofacial adalah trauma akibat ruda paksa terhadap wajah. Trauma maksilofacial terjadi sekitar 6\% dari seluruh trauma. Lebih dari 3 juta trauma fasial terjadi di Amerika Serikat setiap tahun. Trauma fasial menyebabkan fraktur fasial yang banyak terjadi. Pada 2001, sebanyak 24.298 penderita memerlukan pembedahan maksilofacial untuk trauma pada wajah dan rahang. Trauma maksilofacial pada tahun 2011 di Royal Brisbane Hospital (Queensland) meningkat 28\% pada periode 10 bulan yang sama dibandingkan pada tahun 2010. ${ }^{1,2}$

Kecelakaan kendaraan bermotor bertanggung jawab untuk $60 \%$ fraktur fasial, serta sisanya adalah penyerangan $24 \%$, jatuh $9 \%$, kecelakaan industri $4 \%$, olahraga $2 \%$, dan tembakan senjata $2 \%$.

Tergantung pada pusat trauma, jumlah penderita trauma fasial akibat penyerangan bersaing dengan kecelakaan kendaraan bermotor. Diantara trauma akibat olahraga, tinju yang terutama dihubungkan dengan trauma fasial yang insidensnya tinggi. Dalam rangkaian lebih dari 200 fraktur fasial yang terlihat di pusat trauma perkotaan, penyerangan dilaporkan hampir 50\%.6 Rasio pria dibanding wanita 3:1 untuk dewasa, tetapi rasio ini berkurang pada pasien anak-anak 3:2. ${ }^{4,5}$

Fraktur tulang fasial terjadi karena beban trauma yang lebih besar dari tahanan tulang fasial. Fraktur fasial dibagi menjadi beberapa bagian, yaitu fraktur tulang hidung, fraktur zigoma dan arkus zigoma, fraktur maksila, fraktur orbita dan fraktur mandibula., ${ }^{3,5}$

Tulang hidung adalah struktur fasial yang paling sering mengalami fraktur, dilaporkan kira-kira 40\% dari tulang yang mengalami fraktur pada trauma fasial. 7 Pada waktu penyerangan, tulang hidung, tulang mandibula dan tulang zigoma adalah tulang yang paling umum mengalami fraktur. 6,7

Fraktur fasial dapat menyebabkan beberapa komplikasi, antaranya adalah obstruksi saluran napas, perdarahan, gangguan pada vertebra servikalis atau terdapatnya gangguan fungsi saraf otak. Penanganan khusus pada fraktur/trauma fasial, harus dilakukan segera (immediate) atau pada waktu berikutnya (delayed). ${ }^{8,9}$

Penanggulangan ini tergantung kepada kondisi jaringan yang terkena trauma. Pada periode akut setelah terjadi kecelakaan, tidak ada tindakan khusus untuk fraktur fasial kecuali mempertahankan jalan napas, mengatasi perdarahan dan memperbaiki sirkulasi darah serta cairan tubuh. Tindakan reposisi dan fiksasi definitif bukan tindakan life-saving. Dengan peningkatan mobilisasi penduduk serta tingkat transportasi yang berkembang, menyebabkan insiden kecelakaan yang menyebabkan trauma fasial meningkat. ${ }^{10,11,12}$

\section{METODOLOGI PENELITIAN}

Penelitian ini menggunakan metode retrospektif deskriptif melalui penelitian data rekam medik penderita fraktur fasial di SMF Bedah BLU RSU Prof. Dr. R.D. Kandou Manado periode Januari 2012 sampai Desember 2012. Data primer diambil dari bagian rekam medik dengan diagnosa fraktur fasial yang meliputi, fraktur tulang-tulang mandibula, maksila, zigoma, dan tulang nasalis.

Mengumpulkan data berdasarkan catatan status semua penderita yang didiagnosis sebagai kasus fraktur fasial. Data kemudian dikelompokkan berdasarkan variabel penelitian kemudian disajikan dalam bentuk teks dan tabel, selanjutnya dianalisa berdasarkan presentase.

\section{HASIL PENELITIAN DAN BAHASAN}

Berdasarkan hasil penelitian retrospektif deskriptif di SMF Bedah BLU RSU Prof. Dr. R.D. Kandou Manado, jumlah penderita fraktur fasial yang dirawat di SMF Bedah periode Januari 2012Desember 2012 sebanyak 156 kasus (5,60\%) dari 2786 trauma fasial yang dirawat.

Pada Tabel 1 diperoleh jumlah penderita fraktur fasial terbanyak ditemukan pada golongan umur 20-29 tahun sebanyak 78 kasus (50,00\%). Usia ini (20-29 tahun), 
adalah usia produktif dengan mobilitas tinggi sehingga mereka rentan terhadap kecelakaan jalan raya atau kecelakaan kerja. Beberapa penelitian lain juga menunjukkan bahwa rentang usia ini paling banyak mengalami kecelakaan yang menyebabkan trauma fraktur pada wajah (Martin dkk). ${ }^{13}$

Pada tabel 2 diperoleh bahwa penderita fraktur fasial terbanyak ditemukan pada pria sebanyak 132 kasus (84,62\%) dibandingkan pada wanita sebanyak 24 kasus (15,38\%). Hasil ini sama dengan penelitian yang dilakukan oleh Martins Jr dkk di Blumenau, Santa Catarina pada tahun 2004-2009 dimana penderita fraktur fasial terbanyak ditemukan pada pria sebanyak 178 kasus (80,18\%) sedangkan pada wanita sebanyak 44 kasus (19,82\%).Kepustakaan juga menuliskan rasio pria dibanding wanita $3: 1{ }^{13}$

Pada tabel 3 diperoleh bahwa penderita fraktur fasial terbanyak ditemukan pada penderita yang memiliki pekerjaan sebagai pegawai swasta sebanyak 40 kasus (25,64\%). Hasil ini hampir sama dengan penelitian yang dilakukan oleh Martins $\mathrm{Jr}$ dkk di Blumenau, Santa Catarina pada tahun 2004-2009 dimana penderita fraktur fasial terbanyak ditemukan pada pegawai/ karyawan (employee). Sedangkan penelitian yang dilakukan Montovani et all (2006) menemukan penderita fraktur fasial terbanyak pada mahasiswa/siswa. ${ }^{14}$

Pada Tabel 4 diperoleh bahwa penderita fraktur fasial terbanyak ditemukan pada penderita yang memiliki alamat di kecamatan Malalayang sebanyak 49 kasus (31,41\%). Lebih banyaknya penderita fraktur fasial yang memiliki alamat di kecamatan Malalayang kemungkinan oleh karena letak RSU Prof. Dr. R.D. Kandou Manado yang berada di kecamatan Malalayang sehingga masyarakat yang tinggal di kecamatan ini bila menderita fraktur langsung datang ke rumah sakit ini yang lebih dekat supaya lebih cepat mendapatkan pertolongan.

Pada Tabel 5 diperoleh bahwa penderita fraktur fasial terbanyak disebabkan oleh kecelakaan lalu lintas sebanyak 82 kasus (52,56\%). Hasil ini berbeda dengan penelitian yang dilakukan oleh Martins $\mathrm{Jr}$ dkk di Blumenau, Santa Catarina pada tahun 2004-2009 dimana penderita fraktur fasial terbanyak disebabkan oleh penyerangan sebanyak 79 kasus (36\%). Beberapa kepustakaan menunjukkan bahwa jumlah penderita fraktur fasial akibat penyerangan bersaing dengan kecelakaan kendaraan bermotor. Dalam rangkaian lebih dari 200 fraktur fasial yang terlihat di pusat perkotaan, penyerangan dilaporkan terjadi hampir 50\%. ${ }^{14}$

Pada Tabel 6 diperoleh bahwa lokasi fraktur terbanyak pada penderita fraktur fasial ditemukan pada tulang mandibula sebanyak 70 kasus (39,77\%). Hasil ini hampir sama dengan yang dilaporkan oleh Chrcanovic et al. (2004) pada studi dari 1326 fraktur fasial pada 911 kasus, bahwa fraktur tulang fasial lebih banyak pada tulang mandibula, diikuti oleh tulang zigoma dan tulang hidung. 15 Demikian juga dengan penelitian yang dilakukan oleh Martins Jr dkk di Blumenau, Santa Catarina pada tahun 2004-2009 bahwa lokasi fraktur terbanyak pada penderita trauma fasial ditemukan pada tulang mandibula sebanyak 94 kasus $(35,87 \%){ }^{14,15}$

\section{SIMPULAN}

Trauma wajah yang menyebabkan fraktur fasial yang masuk di SMF bedah RSU Prof R. D. Kandou masih cukup tinggi, dan paling banyak akibat kecelakaan lalulintas, maka perlu dilakukan penyuluhan bagi masyarakat pentingnya tertib berkendara serta menggunakan pelindung kepala sekaligus wajah atau menggunakan sabuk penangaman saat berkendara.

\section{DAFTAR PUSTAKA}

1. Steward C., Fiechtl JF, Wolf SJ. Maksilofacial Trauma.: Challenges in ED Diagnosis and Management. An EvidenceBased approach to Emergency Medicine. Emergency Medicine Practice. Volume 10. Num.2. p.1-2

2. Adamo AK., Geibe J. Initial Evaluation and Management of Maxillofacial Injuries. Medscape Reference. June 2012. 
3. Frey R. Craniofacial Reconstruction. The Gale Encyclopedia of Surgery. Vol. 1. 2008. p. 363

4. Lynham A., Tuckett J., Warnke P. Maksilofacial Trauma. Australian Family Physician Vol. 41. No. 4. April 2012. p 172

5. O’Donovan DA., Antonyshyn OM. Maxillary Fractures. Fasial Trauma. p.335336

6. Kelly P, Crawford M, Higuera S, Hollier LH. Two hundred ninety-four consecutive fasial fractures in an urban trauma center: Lessons learned. Plast Reconstructive Surg. 2005;116:42e-49e.

7. Bartkiw TP, Pynn BR, Brown DH. Diagnosis and managment of nasal fractures. Int J Trauma Nurs. 1995;1:11-18.

8. Hoyt DB, Coimbra R, Potenza B. Management of Acute Trauma. Sabiston Textbook of Surgery. p. 502-504
9. Sjamsuhidajat R, De Jong W. Buku Ajar Ilmu Bedah. Ed.2. Jakarta. Penerbit Buku Kedokteran EGC.

10. Ochs MW, Tucker MR. Management of Facial Fractures. Oral and Maxillofacial Trauma. p. 537-557.

11. Murr AH. Maxillofacial Trauma. p. 224234.

12. Perry M. Emergency Care in Facial Trauma. p. $875-893$

13. Chao MT. Facial Trauma, Sports-Related Injuries.

14. Martins jr JC, Keim FS, Helena ET. Epidemiological Characteristic of Trauma Patients Maxillofacial Surgery at the Hospital Geral de Blumenau SC From 2004 to 2009. International Archives of Otorhinolaryngology. Vol.14. Num.2. 2010.

15. Montovani et al. Etiologia e incidencia das fracturas faciais em adultos e criancas: experiencia em 513 casos. Rev Bras Otorrinolaringol. 2006, 72(2):235-41. 